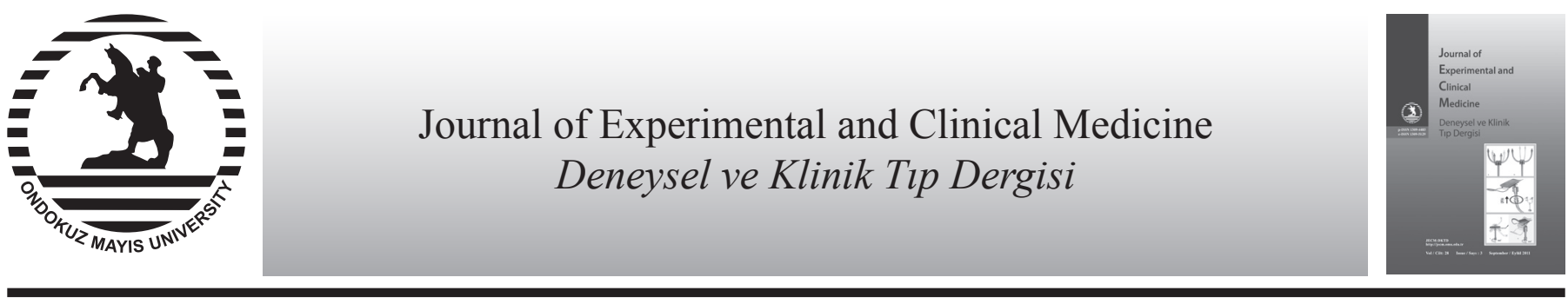

Clinical Research

doi: $10.5835 /$ jecm.omu.28.03.006

\title{
How necessary is computed tomography in pediatric minor head trauma?
}

\author{
Mesut Mete $^{a^{*} \text {, Yusuf Kurtuluş Duransoy }}{ }^{\mathrm{b}}$ Özgür Karabıyık ${ }^{\mathrm{c}}$, Füsun Demirçivi Özer ${ }^{\mathrm{d}}$, Mehmet Selçuki \\ ${ }^{a}$ Department of Neurosurgery, Nevşehir State Hospital, Nevşehir, Turkey \\ ${ }^{b}$ Department of Neurosurgery, Celal Bayar University, Faculty Medicine, Manisa, Turkey \\ ${ }^{c}$ Department of Radiology, Nevşehir State Hospital, Nevşehir, Turkey \\ ${ }^{d}$ Department of Neurosurgery, Izmir Tepecik Training and Research Hospital, İzmir, Turkey \\ ${ }^{e}$ Department of Neurosurgery, Celal Bayar University Faculty Medicine, Manisa, Turkey
}

\begin{tabular}{|c|c|}
\hline$\overline{\text { ARTICLF }}$ & \\
\hline Article Hi & \\
\hline Received & $22 / 07 / 2011$ \\
\hline Accepted & $23 / 07 / 2011$ \\
\hline
\end{tabular}

\section{* Correspondence to}

Mesut Mete

Nevşehir State Hospital

Neurosurgery Department

Ragip Uner Mahallesi

102 Sokak 24/6 Nevşehir

e-mail: dr.mmete@hotmail.com

\section{Keywords:}

Minor head trauma

Cranial computed tomography

Linear fracture

Depressed fracture

Soft tissue swelling

Deep incision

\section{ABSTRACT}

Computerized tomography (CT) is very often used for head injury. Especially in childhood as related to the use of CT is known that a number of drawbacks. At the age of fifteen and under with minor head trauma, it is very difficult to assess whether CT is necessary. The purpose of this study was to assess the necessarity of CT in children who are at 15 years of age and under with minor head trauma. The records of 115 cases who applied with minor head trauma between October 2010-June 2011 to Nevşehir State Hospital Emergency Department, were examined retrospectively. Cases who are 15 years of age and under, with a score of Glascow Coma Scale 15, with a normal neurological examination and applied to emergency service after falls (falls from height, falling from a bicycle, falling on leisure activities), motor vehicle accident, crash and assault were included to study. Forty three (37.4\%) were female and $72(62.6 \%)$ were male, while the average age was 7 . Among the symptoms, vomiting was the most frequent with $30.4 \%$, while headache was in second place with $19.1 \%$. When we look at the findings, soft tissue swelling was $29.6 \%$ in the first place. In all cases CT was taken. Ninety seven (84.4\%) patients had normal CTs, while $18(15.6 \%)$ patients had pathology in cranial CT. In cases with pathological cranial CT, $11(61.1 \%)$ patients had linear fracture, $5(27.7 \%)$ patients had depressed fractures, $1(5.5 \%)$ patient had subdural hematoma plus linear fracture and $1(5.5 \%)$ patient had plastering epidural hematoma. In these patients with pathologic cranial CT, 5 (27.7\%) of them, (overall 4.3\%) underwent surgery. In this study $29.4 \%$ of all patients with soft tissue swelling, and $83.3 \%$ of all patient with deep incision had pathological cranial CT. There were statistically significant difference between presence of soft tissue swelling, deep incision and pathological cranial CT. (Respectively $p=0.009$ and $p=0.001)$. In children 15 years age and under with minor head trauma, cranial CT should be taken in the presence of soft tissue swelling and deep incision in physical examination.

J. Exp. Clin. Med., 2011; 28:107-110

\section{Introduction}

Minor head traumas are significant part of childhood injuries (Savitsky et al., 2000; Beaudin et al., 2007). Trauma mechanisms can be variable, but most often falls (falls from heights, falls on leisure activities, falling from a bicycle), motor vehicle accidents, assaults are as revealed. While the most common mechanism of injury is falls in children under 2 years of age, (Tintinalli et al., 2004) pedestrian and bicycle accidents are more common in children between the ages of 2-15. The incidence of intracranial pathology in children with minor head trauma varies between 3-5\% (Dietrich et al., 1993;
Quayle et al., 1997). However, these pathologies are rarely requires surgical intervention (Quayle et al.,1997; Tintinalli et al., 2004; Schnadower et al., 2007). Most children with minor head trauma apply to emergency service with minimal symptoms or asymptomatic (Tintinalli et al., 2004). In literature, there is no standard definition for minor head trauma. In different sources, patients with the Glasgow coma scale (GCS, Table 1) 13-15, 14-15 or 15 is used for minor head trauma (Dacey et al., 1986; Rivara et al.,1989; Dietrich et al., 1993). However, the recently American Academy of Pediatrics (AAP) defined minor head trauma in children, with the 
initial physical examination, a normal mental status and normal neurologic examination without findings of abnormal or non-bone head fractures as physically (Bergman et al., 1999). Of the GCS is 13 or under as a result of head trauma, amnesia, loss of consciousness, vomiting, suspected skull fracture, the use of anticoagulants, increasing the severity of headache, focal neurological deficit, asymmetric pupillary and multiple trauma as a high-risk criteria are included scanning of cranial CT in the diagnostic algorithm (Kirsch et al., 2000). In different studies for minor head trauma in children, clinician to request diagnostic tests as a cranial CT rate varies between 5-50\% (Quayle, 1999).

\section{Materials and methods}

One hundred and fifteen patients admitted to the Nevsehir State Hospital emergency department between October 2010 - June 2011 with minor head trauma were examined retrospectively. The patients who are 15 years of age and under, with GCS $=15$, neurological examination was normal and applied to emergency service with minor head trauma as a result of the motor vehicle accidents, falls (falls from height, falling from a bicycle, falling on leisure activities), attack have been included in this study. Patients records and clinical files in regard to age, gender, reason for application (fall, vehicle accident, crash, other) and time, the presence of neglect is suspected, symptoms (nausea, vomiting, loss of consciousness, crying/irritability, lethargy, other), the findings (soft tissue swelling, abrasions, deep incision, superficial incision, other), cranial computed tomography findings, result in the necessity and form of operation (discharge, hospitalization, surgery) were recorded.

\section{Statistical analysis}

Evaluation of the data obtained from the SPSS 15.0 statistical program was used. In the comparison of categorical data, Pearson Chi Square test was used. Averages supplied with a standard deviation and, the significance level of $p<0.05$ was adopted in all analysis.

\section{Results}

Included of 115 cases in this study, 43 (37.4\%) were female and $72(62.6 \%)$ were men, while the average age was 7 .When we look at the reasons for the application; 78 (67.8\%) patients with fall, $23(20 \%)$ patients with motor vehicle accidents and $14(12.2 \%)$ patients applied for other reasons. All patients admitted to in the first 24 hours after the incident. Distributions based on symptoms, vomiting were the first reference with $30.4 \%$, while headache was in second place with $19.1 \%$. Percent of patients with pathological cranial CT $5(27.7 \%)$ had vomiting, $3(16.6 \%)$ had headache, $3(16.6 \%)$ had lethargy and $1(5.5 \%)$ had crying/restlessness complaint is available in 6 patients had no symptoms. There were no statistically significant difference between patients with symptoms and without symptoms when compared for pathologic cranial CT ( $>0.05)$. Table 1 shows the distribution of symptoms. When we look at the findings, soft tissue swelling is the first place with $29.6 \%$, while abrasion ranked second with the $20 \%$. The patients with pathologic cranial CT, 10 (55.5\%) patients had soft tissue swelling, 5 (27.7\%) patients had the deep incision in scalp, $2(11.1 \%)$ patients had abrasions, and 1 (5.55\%) patient had superficial incision in scalp. In cases with pathologic cranial CT, $11(61.1 \%)$ patients had linear fracture, $5(27.7 \%)$ patients had depressed fractures, $1(5.5 \%)$ patient had subdural hematoma plus linear fracture and $1(5.5 \%)$ patient had plastering epidural hematoma. Clinical findings identified in all patients, who had pathologic cranial CT but in patients with clinical findings, pathologic cranial CT was found in $24.6 \%$. All patients without clinical findings had normal cranial CT. There were statistically significant difference between patients with clinical findings and without clinical findings when compared for pathologic cranial CT $(p<0.001$, Table 2$)$. When we think of those findings separately, $29.4 \%$ of patients with soft tissue swelling, $8.6 \%$ of patients with abrasion, $10 \%$ of patients with superficial incision and $83.3 \%$ patients with deep incision in scalp had pathologic cranial CT (Table 3). There were statistically significant difference between presence of soft tissue swelling, deep incision and pathological cranial CT. (Respectively $\mathrm{p}=0.009$ and $\mathrm{p}=0.001)$.

Table 1. The distribution of clinical symptoms in children with minor head injury

\begin{tabular}{|l|l|}
\hline Symptoms & Number of cases (n) /percentage (\%) \\
\hline Vomiting & $35(30.4 \%)$ \\
\hline Headache & $22(19.1 \%)$ \\
\hline Lethargy & $16(13.9 \%)$ \\
\hline Crying/restlessness & $6(5.2 \%)$ \\
\hline
\end{tabular}

Result in the cases, 97 (84.4\%) is being discharged from the emergency department while $18(15.6 \%)$ patients were hospitalized for observation and surgery. 13 patients discharged after clinical follow up and other 5 patients with depressed fracture, discharged after surgery.

\section{Discussion}

The selection of imaging techniques in pediatric patients with minor head injury, any of the clinical findings that increasing the relative risk of structural brain injury, patients may not have any clinical, findings can be found alone or in combination (Savitsky et al., 2000).

Haydel et al., (2003) reported in their study with children 5-17 years of age with minor head trauma, $8 \%$ cases had cranial fracture or intracranial pathology on CT and 7.1\% of these required operations. Borzcuk et al., (1995) reported 1211(83.6\%) patients had Glaskow Coma Scale 15 in 1448 cases. Five point nine percent of these patients had pathologic cranial CT and only 1 patient underwent surgery. They

Table 2. Statistical comparison of clinical findings and cranial CT with chi-square tests

\begin{tabular}{|l|l|l|}
\hline Clinical findings & CT normal & CT abnormal \\
\hline There & $55(47.8 \%)$ & $18(15.6 \%)$ \\
\hline No & $42(36.5 \%)$ & 0 \\
\hline
\end{tabular}

Table 3. Distribution of the clinical findings identified in children with minor head trauma

\begin{tabular}{|l|l|}
\hline Clinical findings & Number of cases (n) /percentage (\%) \\
\hline Soft tissue swelling & $34(29.6 \%)$ \\
\hline Abrasion & $23(20 \%)$ \\
\hline Superficial incision in scalp & $10(8.7 \%)$ \\
\hline Deep incision in scalp & $6(5.2 \%)$ \\
\hline
\end{tabular}


suggested for patients with $\mathrm{GCS}=15$, cranial $\mathrm{CT}$ may also be taken less in emergency department. In our study, patients who underwent cranial CT imaging, pathology detected at $15.6 \%$ and $61.1 \%$ of them had the linear fracture, $27.7 \%$ had depressed fractures, $5.5 \%$ had linear fractures plus subdural hematoma and $5.5 \%$ had plastering epidural hematoma.

Türedi et al., (2008) suggested in their study which include child and adults with minor head trauma, patients with GCS $=15$ and with low criteria (without high risk criteria like GCS is under 13 as a result of head trauma, amnesia, loss of consciousness, vomiting, suspected skull fracture, the use of anticoagulants, increasing the severity of headache, focal neurological deficits, such as asymmetrical pupil and multiple trauma) can be discharged safely without cranial CT scan. In this study, low-risk patients with minor head trauma, an abnormal cranial CT was $6 \%$, none of the patients did not need surgery. Stein and Ross, (1992) reported in their study 1117 patients were GCS=15 in 1538 cases. $13.2 \%$ of them had pathologic cranial CT. They suggested cranial CT scan should be taken if patients have loss of consciousness and post-traumatic amnesia. In our study, patients with deep incision, $5(83.3 \%)$ of them had pathologic cranial CT and 5 patients had surgery because of the depressed fractures.

Gutman et al., (1992) found, cases with falling have more traumatic intracranial injury then other trauma mechanisms. Borzcuk et al., (1995) reported that children with motor vehicle and bicycle accident are more inclined for intracranial injury. In our study, $30.4 \%$ of the cases that came with the car accident, $12.8 \%$ of the cases came with falling and $7.1 \%$ of the cases came with beaten-crash pathology was found in cranial CT.

Miller et al., (1995) reported that headache is not a risk factor for detection of pathologic cranial CT. In our study, only 3 of 18 patients who have pathological cranial CT had headaches. In patients with complaints of headache, $13.6 \%$ of them had pathological Cranial CT, $16.1 \%$ of them had normal cranial CT, and there was no statistically significant difference between presence of headache and detection of pathologic cranial CT $(\mathrm{p}>0.05)$.

Duus et al., (1994) reported patients, with minor head trauma, can safely discharged with clinical findings and physical examination without any imaging method. Schunk et al. (Schunk et al.,1996) reported in their study with pediatric age group, nausea and vomiting are not risk factors in minor head trauma patients for the detection of pathological cranial CT. In our study $30.4 \%$ of all head-injured patients and $27.7 \%$ of those who have pathological cranial CT had vomiting and there was no statistically significant difference between vomiting and presence of pathologic cranial CT. $14.2 \%$ of patients with complaints of vomiting, $16.2 \%$ of patients without complaints of vomiting had pathologic cranial CT. However, no statistically significant difference was found between the two groups ( $\mathrm{p}>0.05)$.

In several studies, radiation is seen to increase the risk of cancer (C-Infante Rivard et al., 2000; David et al., 2007). C- Infante Rivard et al., (2000) have shown X-ray increased risk of acute lymphoblastic leukemia in pediatric patients as a result of polymorphisms in DNA repair genes. David Brenner et al. (David et al., 2007) reported that X - ray increases the risk of cancer by DNA mutations, chromosomal translocations and fusion gene and on the rate of 1.5 to $2 \%$ of all cancers in the United States may be due to the use of tomography.

In conclusion, we have dealt with the mechanism of trauma, vomiting, headache, lethargy, crying, restlessness, and similar clinical variables as in many studies in literature affect the physician for prompt cranial CT. In our patient group $\mathrm{GCS}=15,29.4 \%$ of all patients with soft tissue swelling and $83.3 \%$ of all patients with deep incision had pathological cranial CT. There were statistically significant difference between presence of soft tissue swelling, deep incision and pathological cranial CT (respectively $\mathrm{p}=0.009$ and $\mathrm{p}=0.001$ ). Pathological cranial CT rate is $15.6 \%$ (18 patients) and 5 of these patients underwent surgery due to depressed fracture. Given the increased risk of cancer with unnecessary tomography, patients admitted with head injury to emergency service, GCS $=15$ and pathology could not be identified on physical examination of pediatric patients should be kept under observation and could discharged after 24 hours. Whereas the GCS 15, on physical examination presence of findings such as soft tissue swelling and deep incision may accompany to linear fracture and depressed fracture. We suggest that in the presence of these clinical findings cranial CT should be taken although Glascow Coma Scale shows 15 points for any particular patient.

\section{REFERENCES}

Beaudin, M., Saint-Vil, D., Ouimet, A., 2007. Clinical algorithm and resource use in the management of children with minor head trauma. J. Pediatr. Surg. 42, 849-852.

Bergman, D.A., Baltz, D.R., Coolye, J.R., 1999. The management of minor closed head injury in children. Pediatr. 104, $1407-1416$.

Borzcuk, P., 1995. Predictors of Intracranial Injury in patients with Mild Head Injury. Ann. Emerg. Med. $25,731$.

Infante-Rivard, C., Mathonnet, G., Sinnett, D., 2000. Risk of childhood leukemia associated with diagnostic irradiation and polymorphisms in DNA repair genes. Environ. Health Perspect. 108, 495-498.

Dacey, R.G., Alves, W.M., Rimel, R.W., 1986. Neurosurgical complications after apparently minor head injury: Assessment of risk in a series of 610 patients. J. Neurosurg. 65, 203-210.

David, J., Phil, D., Eric, J., 2007. Computed Tomography - An Increasing source of radiation exposure. N. Engl. J. Med. 357, $2277-2284$.

Dietrich, A.M., Bowman, M.J., Ginn-Pease, M.E., 1993. Pediatric head injuries: can clinical factors reliably predict an abnormality on computed tomography? Ann. Emerg, Med. 22, 1535-1540.

Duus, B.R., Lind, B.,Christensen, H., 1994. The role of neuroimaging in the initial management of patients with minor head injury. Ann. Emerg. Med. 23, 1279.

Gutman, M.B., Moulton, R.J., Sullivan, I., 1992. Risck factors predicting operable intracranial hematomas in head injury. J. Neurosurgry. 77, 9.

Haydel, M.J., Shembekar, A.D., 2003. Prediction of intracranial injury in children aged five years and older with loss of consciousness after minor head injury due to nontrivial mechanisms. Ann. Emerg. Med. 42, 507-514. 
Kirsch, T.D., Migliore, S., Hogan, T.M., 2000. Head injury in: Emergency medicine, 5th edition. New York: McGraw Hill. $1631-1645$.

Miller, E.C., Derlet, W.R., Kinser, D., 1995. Minor head trauma is computed tomography always necessary? Ann. Emerg. Med. $27,290$.

Quayle, K.S., 1999. Minor head injury in the pediatric patient. Pediatr. Clin. North. Am. 46, 1189-1199.

Quayle, K.S., Jaffe, D.M., Kuppermann, N., 1997. Diagnostic testing for acute head injury in children: when are head computed tomography and skull radiographics indicated? Pediatrics. 99, 11.

Rivara, F.P., Calonge, N., Thompson, R.S., 1989. Population - based study of unintentional injury incidence and impact during childhood. Am. J. Public. Health. 79, 990-994.

Savitsky, E.A., Votey, S.R., 2000. Current controversies in the management of minor pediatric head injuries. Am. J. Emerg. Med. 18,96 -101.

Schnadower, D., Vazquez, H., Lee, J., 2007. Controversies in the evaluation and management of minor blunt head trauma in children. Curr. Opin. Pediatr. 19, 258-264.

Schunk, J.E., Rodgerson, J.D., Woodward, G.A., 1996. The utility of head computed tomographic scanning in pediatric patients with normal neurologic examination in the emergency department. Ped. Emerg. Care. 12, 260.

Stein, S.C., Ross, S.E., 1992. Mild head injury: A plea for poutine early CT scanning. J. Trauma. 33,11.

Tintinalli, J., Kelen, G.D., Stapczynski, J.S., 2004. Emergency medicine, Comprehensive study guide american college of physicians. The McGraw-Hill Companies, Inc. Sixth edition, section 22, Pediatric trauma, pp: 1545-1546.

Türedi, S., Hasanbasoğlu, A., Gündüz, A., 2008. Clinical desicion instruments for CT scan in minor head trauma. J. Emerg. Med. 34, $253-259$. 